\title{
Framework for LCI modelling of releases of manufactured nanomaterials along their life cycle
}

\author{
Roland Hischier
}

Received: 2 April 2013 / Accepted: 16 December 2013 / Published online: 11 January 2014

(C) Springer-Verlag Berlin Heidelberg 2014

\begin{abstract}
Purpose Numerous publications in the last years stressed the growing importance of nanotechnology in our society, highlighting both positive as well as in the negative topics. Life cycle assessment (LCA) is amongst the most established and best-developed tool in the area of product-related assessment. In order to use this tool in the area of nanotechnology, clear rules of how emissions of nanomaterials should be taken into account on the level of life cycle inventory (LCI) modelling are required - i.e. what elements and properties need to be reported for an emission of a nanomaterial. The objective of this paper is to describe such a framework for an adequate and comprehensive integration of releases of nanomaterials.

Methods With a three-step method, additional properties are identified that are necessary for an adequate integration of releases of nanomaterials into LCA studies.

Result and discussion In the first step, a comprehensive characterisation of the release of a nanomaterial is compiledbased on reviewing scientific publications, results from expert workshops and publications from public authorities and international organisations. In the second step, this comprehensive overview is refined to a list containing only those properties that are effectively relevant for LCA studies-i.e. properties that influence the impacts in the areas of human toxicity and ecotoxicity, respectively. For this, an academic approach is combined with a second, more practical, view point, resulting
\end{abstract}

Responsible editor: Berlan Rodriguez Perez

Electronic supplementary material The online version of this article (doi:10.1007/s11367-013-0688-8) contains supplementary material, which is available to authorized users.

R. Hischier $(\bowtie)$

Swiss Federal Laboratories for Materials Science and Technology

(Empa), Technology \& Society Lab (TSL)/Environmental Risk

Assessment \& Management Group, Lerchenfeldstrasse 5, 9014 St. Gallen, Switzerland

e-mail: roland.hischier@empa.ch together in a prioritisation of this list of properties. Finally, in a third step, these findings are translated into the LCA language - by showing how such additional properties could be integrated into the current LCA data formats for a broader use by the LCA community.

Conclusions As a compromise between scholarly knowledge and the (toxicological) reality, this paper presents a clear proposal of an LCI modelling framework for the integration of releases of nanomaterials in LCA studies. However, only the broad testing of this framework in various situations will show if the suggested simplifications and reductions keep the characterisation of releases of nanomaterials specific enough and/or if assessment is accurate enough. Therefore, a next step has to come from the impact assessment, by the development of characterisation factors as a function of size and shape of such releases.

Keywords Framework - LCA - LCI modelling - Life cycle assessment - Manufactured nanomaterial - MNM . Nanotechnology

\section{Introduction}

Numerous publications in the last years stressed the importance that nanotechnology, and with this, a whole variety of manufactured nanomaterials ${ }^{1}(\mathrm{MNM})$ are gaining in our society, in the positive as well as in the negative sense (e.g. Handy et al. 2008b; Piccinno et al. 2012). Examples of the latter one are, e.g. the potential toxicological consequences or the environmental impacts due to the production of these MNM (e.g.

\footnotetext{
$\overline{{ }^{1} \text { Nanomaterial' }}$ ' is defined in EC 2011, as 'a natural, incidental or manufactured material containing particles, in an unbound state or as an aggregate or as an agglomerate and where, for $50 \%$ or more of the particles in the number size distribution, one or more external dimensions is in the size range $1-100 \mathrm{~nm}$ '.
} 
Handy et al. 2008a; Sharifi et al. 2012; Klaine et al. 2012). Life cycle assessment (LCA) is the most established and bestdeveloped tool in the area of product-related assessment according to Ness et al. 2007. The implementation of LCA allows the quantification of the impacts on human health and the environment of a product or a system over its entire life cycle (see, e.g. Finnveden et al. 2009) and thus is also an ideal tool to evaluate in this sense MNM and their applications.

\subsection{LCA of manufactured nanomaterials}

Three recent review articles (Gavankar et al. 2012; Hischier and Walser 2012; Upadhyayula et al. 2012) have shown that there are few LCA studies of MNM published to date. Furthermore, the studies that have been completed are far from what is currently considered 'comprehensive' LCA studies. Releases of $\mathrm{MNM}^{2}$ are neglected in almost all studies according to these review articles, and the most recent LCA publications of nanotechnology case studies (Asmatulu et al. 2012; de Figueirêdo et al. 2012; Deorsola et al. 2012; LeCorre et al. 2013 - studies not covered by the above three review articles) again show a lack of these types of emissions. In fact, the only study reporting information about releases of MNM so far is the study of Walser et al. 2011, dealing with nanosilver. This study reports about releases of MNM to water - partly based on direct measurement data, partly as the result of an application of the model described in Gottschalk and Nowack 2011. If other studies report emissions, they only include 'classic' emissions to air respespectively water (like, e.g. carbon dioxide to air, or BOD5-the biological oxygen demand in water). The three reviews mentioned above (Gavankar et al. 2012; Hischier and Walser 2012; Upadhyayula et al. 2012) end with similar conclusions. That is, there is a need to develop protocols/ models for a more appropriate modelling of MNM and their releases as well as to establish first, comprehensive inventory datasets of the production of these materials.

\subsection{Current practice in life cycle inventory modelling}

Important keywords that describe a good life cycle inventory (LCI) dataset are 'transparency' and 'consistency'. Since the first 'code of practice' for LCA was established in a workshop in 1993 (SETAC 1993) and the International Standardisation

\footnotetext{
${ }^{2}$ According to ISO 2010, releases having one or more dimensions in the nanoscale (i.e. in the range $1-100 \mathrm{~nm}$ ) are defined as 'nano objects'; and comprise 'nanoparticles' (all three dimensions in the nanoscale), 'nanofibres' (two dimensions in nanoscale) and 'nanoplates' (one dimension in nanoscale). As reported, e.g. in Klaessig et al. 2011, 'several reports have been issued that differ in definitions used for nanotechnology' - therefore, here the term 'manufactured nanomaterial' (MNM) is used for both, the material as well as its releases along the life cycle.
}

Organisation (ISO) standards about LCA (most recent version in ISO 2006a, b), scores of instruction manuals about establishing LCI data have been published. Important publications in this area are the methodology reports of the ecoinvent database (Frischknecht et al. 2007; Weidema et al. 2012), the ILCD $^{3}$ handbook series (EC-JRC 2010a, b, c, d, 2011) from the European Commission's Joint Research Centre (ECJRC), and the recent workshop report of global LCI specialists, established under the umbrella of the UNEP-SETAC Life Cycle Initiative (Sonnemann and Vigon 2011), summarising the outcomes of an early 2011 workshop in Japan with the objective to establish global guidance principles for LCA databases.

In this paper, the ecoinvent methodology (Weidema et al. 2012) is used as the starting point due to the fact that datasets are reported in this framework on a unit process level. The 'unit process level' shows direct inputs (materials and energy supply) and outputs (emissions and waste) and thus is a wellfitting model to follow for 'transparency' and 'consistency'. According to this methodology, LCI modelling bases each inventory dataset on environmental process chain analysis and represents it on the level of the direct inputs and outputs. There are no fixed, quantitative cut-off rules concerning the inclusion or not of a specific exchange with the nature and/or technosphere applied. Instead, all (occurring) flows are reported in its most meaningful form rather than using a predefined list of elementary flows. And a clear and complete documentation of the whole process and its related flows is established.

\subsection{Application to manufactured nanomaterials}

As for any other type of material, the production inventory of a MNM comprises inputs of raw materials, auxiliaries, and energy carriers on the one hand; waste and emissions to air, water and eventually to soil as outputs on the other hand. The only difference to these 'traditional' materials is the fact that emissions of MNM in production, use or disposal could be not only in bulk ${ }^{4}$ but also in nano form, i.e. have one or more dimension in the nanoscale.

In a review article, $\mathrm{Nel}$ and co-workers stipulated that '[nanomaterial] properties differ substantially from those of bulk materials of the same composition' (Nel et al. 2006). However, so far in LCI modelling no such distinction takes place; instead, all emissions of the same (chemical) composition into one compartment (e.g. into air or water) are summed up and expressed as their total amount (in kilogram). Particle

\footnotetext{
${ }^{3}$ International Reference Life Cycle Data System (ILCD) — published by EC-JRC in order to 'to provide guidance for consistent and quality assured Life Cycle Assessment data and studies'.

${ }^{4}$ The term 'bulk' stands in this paper for materials that does not fit into the European Commission's definition of (manufactured) nanomaterials; i.e. material that has $<50 \%$ of its particles in the number size distribution, one or more external dimensions is in the size range of $1-100 \mathrm{~nm}$.
} 
emissions as such are characterised according to their particle size (i.e. according to the aerodynamic diameter) only, and then reported mass-based. Since its beginning, the ecoinvent Centre distinguishes three different classes of particulate matter (PM) emissions in its database-i.e. a distinction between $\mathrm{PM}>10 \mu \mathrm{m}, \mathrm{PM}$ between 2.5 and $10 \mu \mathrm{m}$ and $\mathrm{PM}<2.5 \mu \mathrm{m}$ is made in order to avoid double counting between the classes. However, neither the current version v3.01 of ecoinvent (ecoinvent Centre 2013) nor recent Life Cycle Impact Assessment (LCIA) publications (e.g. EC-JRC 2011; Goedkoop et al. 2012) have covered the category of $\mathrm{PM}_{0.1}$ (the size category covering MNM) and neither of these sources is considering the composition of PM emissions.

\subsection{Open issues}

Clark reports that a single matrix (i.e. the amount in kilogram) is not sufficient for the comprehensive specification of releases of MNM (Clark et al. 2012). Thus, for LCA studies, clear rules of how releases of MNM need to be taken into account on the level of LCI modelling (i.e. what elements, what properties need to be reported for an emission of a respective $\mathrm{MNM}$ ) are required. The objective of this current paper is the description of such a framework for an appropriate and comprehensive integration of releases of MNM (into air, water or soil) into an LCI model.

\section{Methodological approach}

In principle, releases of MNM can enter into air, water and/or soil (see, e.g. Lin et al. 2010). Gottschalk and co-workers have shown through modelling the individual behaviour of a MNM along the complete life cycle that, e.g. nano- $\mathrm{TiO}_{2}$ and nano$\mathrm{Ag}$ are mainly released into water and soil, while carbon nanotubes (CNTs) end up mainly in air (Gottschalk et al. 2009). Hence, similar as for emissions of (bulk) substances, the flow of an emitted MNM needs to be reported with its (receiving) compartment, whereas all further behaviour is then part of the LCIA modelling (again similar as for (bulk) substances), taking into account the actual behaviour (i.e. the fate) of an emitted substance in the nature as well as its related impacts (i.e. its effects on the environment and on human health).

However, unlike traditional (bulk) substances, the overall impact of the releases of a MNM depends not only on its amount but also on further properties of the emitted particles. Key issue here is thus the identification of these additional properties of a MNM that need to be reported in the inventory part in order to allow in the subsequent LCIA step an adequate assessment of the impacts due to the release of this specific MNM. For the identification of these LCIA-relevant properties, a three-step procedure is considered here, comprising the following three steps:

1. Characterisation of nanomaterials: As starting point, a list of all the properties for a comprehensive characterisation of MNM releases is established. This list is the result of a literature review, including scientific papers, expert workshop reports as well as a broad variety of documents from public authorities and international organisations dealing with issues of safety and occupational health of MNM (details see Section 3).

2. Identification of relevant aspects: In the second step, described in details in Section 4, those properties are identified, that are considered 'LCA-relevant', meaning those properties that affect the impact of an MNM release.

3. Translation into LCA language: The third and final step outlines a way how these LCA-relevant properties shall (on a technical level) be reported within an LCI dataset. Then, this will allow in a subsequent impact assessment an adequate calculation of the related impacts.

Explicitly not part of the procedure described here is a derivation or calculation of characterisation factors (CFs) respectively for the subsequent assessment of the impacts due to MNM releases. Within Eckelman et al. (2012) and Salieri (2013), first values of such CF for CNT and nano$\mathrm{TiO}_{2}$ have been published recently.

\section{Characterisation of nanomaterials (step 1)}

The characterisation of an MNM release by a single matrix (i.e. the mass amount in kilogram) as used for traditional releases (e.g. carbon dioxide to air) is insufficient in order to assess in an appropriate way MNM releases (Clark et al. 2012). Thus, in this first step, a list of the properties that would appropriate characterise an MNM release is established. A literature review for a more comprehensive characterisation of MNM releases has been made here, identifying and analysing relevant scientific (journal) publications, results of expert workshops and disclosures (i.e. reports, tools, etc.) from public authorities and international organisations, active in this issue. The outcome of this review process is summarised in Table 1.

The first two lines of Table 1 contain in fact the two properties that are used to report traditional releases (e.g. carbon dioxide to air): the composition (reported as the substance name) and the amount (reported usually as a mass amount in kilogram). While the substance name is mentioned in a majority of examined sources here as well, the latter one (i.e. the amount) is reported in none of them. However, as the examined sources are all dealing with the issue of 'characterising' MNM-reporting the amount released in a 
Int J Life Cycle Assess (2014) 19:838-849

841

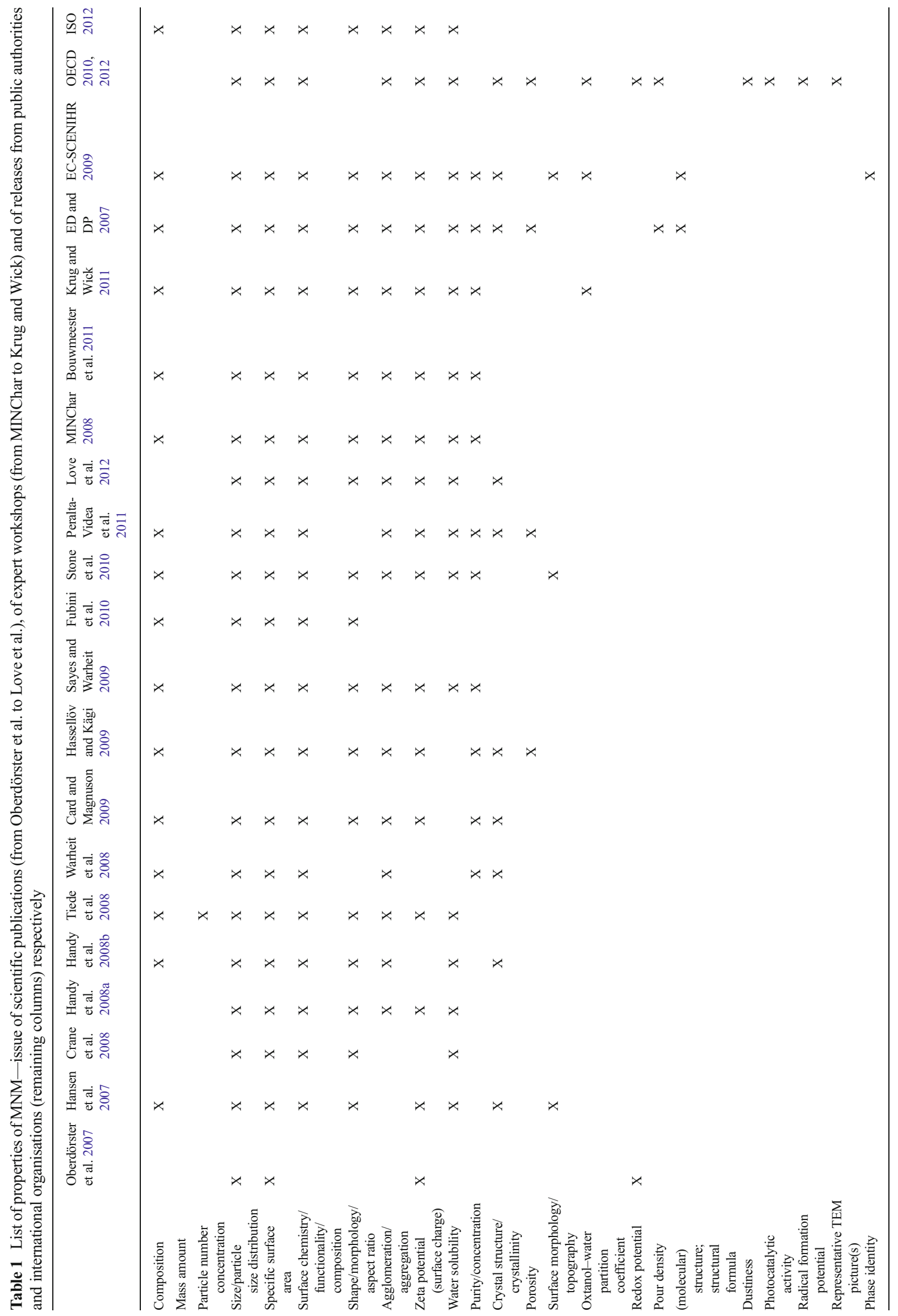

炟 Springer 
(specific) context is simply not of any interest in this type of study. Delving into more detail, studies dealing specifically with releases of MNM to air (e.g. Charron and Harrison 2009; Demou et al. 2009; Motzkus et al. 2011; Walser et al. 2012), it is noted that such releases are often not reported as mass amount but as a particle number concentration. Thus, particle number concentration is listed as the third property. All subsequent properties listed in Table 1 are then grouped according to their number of occurrences in the examined literature sources. A clear cut could be observed after the first dozen of properties (i.e. after the line 'crystal structure/crystallinity') as all further properties are mentioned not more than one to two times (most notably in the reports EC-SCENIHR 2009 and OECD 2010, 2012, respectively).

The frequency of appearance of a specific property in Table 1 is, at least partly, a sign of the ease of measurement of a given property (Charron and Harrison 2009). LCA is at the same time a quantitative tool that requires data in form of actual numbers in order to end up with robust results. Thus, a property cited in many of the sources examined here can be considered as 'important' or 'relevant' for the characterisation of a MNM, and as a consequence, these properties will often be examined in studies about a specific MNM. This kind of properties is then very suitable for LCA studies, as actual numbers will be available and this will result in a more accurate inventory modelling in the end.

As a consequence, the first dozen of factors listed in Table 1-i.e. 'composition' to 'crystal structure/ crystallinity' - is taken as the result from step 1 (and thus, as starting point for step 2), as only properties that can be physically measured can really support LCA studies.

Concerning the measurement of these various properties of MNM releases, according to the findings of 'Nanocap', a recent European Research project there is no method that can be considered the 'best' method (Nanocap 2009). Instead, there exists a multitude of analytical methods that can be used to analyse releases of MNM to water, soil and air.

\section{Identification of LCA-relevant properties (step 2)}

In the second step, this list is refined to contain only those properties, which can be identified as being 'LCA relevant'. According to Smita et al. (2012), 'various environmental processes that depend on the presence of physical entities are likely to be altered by the accumulation of MNM in the environment'. Amongst these processes are the formation of dust clouds, the influence on atmospheric composition, the influence on stratospheric temperature and the accumulation in biological matrices (i.e. toxicity issues). For the present study, the focus is on the last point, i.e. on the impact of this kind of releases in the areas of human toxicity and ecotoxicity since 'toxicity' is by far the most often cited concern in publications dealing with MNM releases to the environment.

\subsection{Literature review}

In a first round, following a traditional academic procedure, a literature review was executed in order to identify those properties that effectively have an influence on the toxicity value of a MNM release. As basis in order to examine the influence of the various properties listed in Table 1, the consensus model for the assessment of (human and eco) toxicity in LCA studies, the USEtox model (Rosenbaum et al. 2008), is used. This LCIA model distinguishes between 'fate', 'exposure' and 'effect' of a release. Literature reviews concerning the influence of specific properties of a released MNM on fate and exposure respectively on effects in the area of (human and eco) toxicity have been conducted - their results can be summarised as following:

- Fate and exposure: The actual environment in air, water, and soil (like, e.g. the ionic concentration, the organic carbon content, the fulvic acid concentration, $\mathrm{pH}$, etc.) are identified as crucial issues concerning the actual behaviour of MNM in view of their transformation and their release (Farré et al. 2011; Lin et al. 2010). On the level of their own properties the issues of size, surface chemistry and surface charge - together with particle concentration-are identified being the most relevant properties of releases of MNM (Lin et al. 2010; Peralta-Videa et al. 2011; Sanchís et al. 2012). In case of releases into water, the solubility of the released MNM is an additional important property (Labille and Brant 2010). Several recent publications (Alvarez et al. 2009; Lowry et al. 2010; Stone et al. 2009) note that, for the moment, only a few studies are dealing with the influence of 'fate' and 'exposure' by specific MNM properties. A complete list of the here reviewed studies can be found in the Electronic Supplementary Material.

- Effects: Switching the focus to toxicological effects (on human beings respectively on the environment) of MNM releases, the number of available reports and publications is much larger. Of the studies examined, the composition, the size/particle size distribution, the surface chemistry and the zeta potential (surface charge) are identified as the most important and relevant properties of MNM toxicity (see, e.g. Choi and Choy 2011; Schrand et al. 2010; Sharifi et al. 2012). In Warheit et al. 2009, surface chemistry is shown as the most important factor in relation to the toxicity of such a material; while in Choi and Choy 2011, the actual composition of a MNM released is considered the most fundamentally important property. In case of metals and metal oxides, water solubility is highlighted as another important property (Aschberger 
et al. 2011; Scown et al. 2010). In case of shape/ morphology, agglomeration/aggregation and the specific surface area, the sources reviewed here do not provide clear conclusions - the information found is either incomplete (e.g. Handy et al. 2008b, concerning issue of shape/ morphology) is somehow unclear and/or is contradictory. While Horie and Fujita (2011) stipulates that specific surface area is not relevant, Choi and Choy (2011) and Schrand et al. (2010) together with several other studies report exactly the opposite opinion concerning this property. A complete list of the here reviewed studies can be found agin in the Electronic Supplementary Material.

Thus, based on the academic approach - taking into account the knowledge identified about the influence of MNM properties on fate and exposure respectively on the effect of releases of this MNM into the environment - the quasi-complete list of the first dozen of factors in Table 1 can be considered as 'LCA relevant' and therefore should be taken into account. However, only one part of these factors is clearly identified in the literature as having an influence. For the remaining properties, this is not clear for the moment — and thus, based on a precautionary approach, they have to be considered (for the moment at least) as relevant, too.

\subsection{Practicality and prioritisation}

In a second round, the issue of refining the list to 'LCA-relevant' properties is tackled from a more practical viewpoint. The objective was to achieve a reduction of the list above while keeping a meaningful balance between simplifications and the accuracy of the subsequent impact assessment results on an LCA study. In this context, the following issues were examined further with the support of expert interviews ${ }^{5}$ and an additional literature review: taking a (qualitative) life-cycle view, identifying key drivers for human toxicity and examining the mechanisms and factors behind decision tools for a safe use:

- Life cycle view: the potential releases of MNMs were investigated through the whole life cycle of an application of a given MNM (e.g. Köhler et al. 2008, for two application cases of CNTs). An important aspect in this context is that releases of MNM along the life cycle often do not have the same properties compared with the original MNM used in production (i.e. pristine MNM). Thus, they may potentially behave different than the original MNM (Klaine et al. 2012; Nowack et al. 2012). A consequence of this is that in an LCA study, each single life-stage needs to be treated a priori separately and independently from the preceding or subsequent life stages. Unfortunately,

\footnotetext{
${ }_{5}^{5}$ Prof. Dr. Harald Krug, Dr. Peter Wick (both for human toxicity) and Prof. Dr. Bernd Nowack (for ecotoxicity) have been interviewed in the framework of these activities.
}

research is currently focussed mainly on pristine MNM alone (Nowack et al. 2012). However, this currently applied approach results in a lack of information concerning the properties of released MNM in the various life stages.

- Key drivers for human toxicity: The bodies' uptake capacity is a crucial issue in terms of MNM toxicity and the lungs are probably the main entry point for uptake of MNM into the human body (Krug and Wick 2011). According to a recent review, human toxicity depends on the concentration of MNM ingested, in addition to the size, shape, surface and corona (by adhering macromolecules from the host) of the inhaled MNM particles (Kendall and Holgate 2012). Not all MNM sizes and shapes allow easy entry of a particle into the alveoli (the exchange zone of the lung) and so this is an important parameter in terms of toxicity. MNM surface and corona may determine the actual effects of MNM in the human body, then, e.g. the surface represents the actual interface for (positive or negative) interactions between particles and the body (Kendall and Holgate 2012).

- Decision tools for safe MNM use: Investigating various decision support approaches for a safe implementation of MNM (like done, e.g. in Som et al. 2013) results in a rather similar pattern concerning the most relevant issues, i.e. 'size', 'surface reactivity', 'high aspect ratio' (shape), 'no or slow dissolution' (solubility), 'no agglomeration' and 'not being firmly integrated into a matrix material' (surface chemistry/functionality).

Hence, based on this information and regarding the various properties listed in Table 1, the following prioritisation can be established:

First priority-i.e. important aspects that are specific to MNM release:

- Shape: An MNM of a given elemental composition can be produced with different shapes (e.g. Starbova et al. 2012, reporting fibrous forms of nano- $\mathrm{TiO}_{2}$ and nano- $\mathrm{ZnO}$; or Euliss et al. 2006, for a more generic overview). Each shape could result in different consequences e.g. when taken up by the body.

- Size (distribution): This aspect allows the distinction between release of MNM and releases of the bulk form of a material (see also the definition for MNM in Section 1 of this paper). Albanese and co-workers state in a recent publication that, within a given shape, the size distribution has a major influence on the likelihood a biological system will uptake MNM and on subsequent toxicological effects (Albanese et al. 2012). According to Bakand et al. (2012), this is the most relevant property in terms of toxicity potential.

- Surface chemistry and properties: According to Kendall and Holgate (2012), the actual surface conditions (e.g. chemistry, charge and roughness) are a third relevant 
property of released MNM. Surface coatings can influence - in a positive or in a negative sense - the toxicological effects of released MNM. The surface charge has an influence on the absorption capability for ions and biomolecules, and the roughness is a critical factor for interactions with cells (Sharifi et al. 2012). As is clearly shown by Pettitt and Lead (2013), the specific surface area is a key for an accurate characterisation.

Second priority - aspects relevant for all kind of releases (not only releases of MNM):

- Composition: Chemical composition is crucial information of a MNM or a bulk release to the environment. Then, in both cases, the LCA model is not only based on the total amount of respective emissions but also the effects due to the chemical composition of these emissions (i.e. the impact assessment step is a result of a multiplication of the amount with the effect, for each different chemical composition). Hence, it is of the highest importance to know the chemical composition of a release. Information about the composition is usually given via the substance name (but also via related fields - like CAS number or molecular formula; a more comprehensive overview concerning the information content of LCI datasets can be found, e.g. in Hischier et al. 2001).

- Amount (mass amount and/or particle number concentration): Also the second property taken into account for bulk substances is of crucial importance when dealing with releases of MNM. Then, similar as for bulk material, the magnitude of the impact is usually a (linear) function of the amount, calculated by a multiplication of the amount with the corresponding characterisation factor.

All further properties listed in Table 1 (i.e. 'agglomeration/ aggregation', 'purity/concentration', 'crystal structure/ crystallinity') have not been much stipulated in the documentation of the various decision support approaches examined here, nor mentioned by the experts contacted. Therefore, they can all be considered as a 3rd priority here.

In the context of the LCA framework here, the issue of solubility can be omitted from any further investigation (see also Som et al. 2013) and prioritisation - the issue of 'solubility' is linked to the composition and thus its value is defined via the composition information. A separate inclusion of this property on the level of the LCI modelling is hence not necessary. On the level of impact assessment, this property plays, however, an important role. For example, the high solubility of a MNM released into water leads to a similar impact assessment factor as for the corresponding ionic form of this substance (Krug et al. 2013).

All in all, this second step allowed splitting MNM properties into three levels of priority concerning their respective implementation into an LCA model to ensure modelling is based on releases of MNM along their life cycle.

\section{Translation into LCA language (step 3)}

For a translation of all these MNM properties into a language that LCA tools can understand, the format needs to allow the occurrence and the handling of multiple properties within a single material flow. With ecoSpold v2 (ecoinvent Centre 2010) and ILCD (EC-JRC 2012), two LCA data formats that exist today are able to deal with multiple properties. This functionality was recently added in LCA data formats and gives the LCA community the possibility to integrate mathematical relationships between various properties and/or in relation to further parameters/properties that the user can define (Weidema et al. 2012).

All further explanations here are based on the first of these formats - the ecoSpold v2 format. According to Weidema et al. (2012), each elementary exchange (i.e. each exchange with the environment, like an emission to air) is 'identified by an exchange name, its unit, a compartment and a subcompartment'. The latter two are not changing for releases of MNM. Also such a release can be emitted into air, water, and soil respectively (as compartment)... and there into one of the sub-compartments ${ }^{6}$ that ecoinvent is distinguishing. Besides these defining properties, each flow in ecoSpold v2 can be composed of an arbitrary amount of further properties in order to specify clearly the respective flow.

Using these possibilities of a modern LCA data format, these in Section 4.2 above identified first and second priority properties of releases of MNM to the environment could be translated as shown in Table 2.

This translation shown in Table 2 is the result of the following reasoning for the various properties:

- Composition: The composition continues to be one of the defining elements in the case of MNM releases. It is described, like for any kind of ordinary elementary flows, in form of the name of the respective release.

- Shape: This property is added as an additional property in case of releases of MNM. According to Kendall and Holgate (2012), as well as the experts contacted, a distinction between (asbestos-like) fibres and all other particles is sufficient for an assessment of their toxicological effects. For this distinction, the WHO definition for fibres (i.e. aspect ratio greater than $3: 1$ - see e.g. Donaldson and Tran 2004) is used here. Other particles are assumed to be of

\footnotetext{
$\overline{{ }^{6} \text { Emissions to }}$ air: non-urban air or from high stacks/low population density, long term/lower stratosphere+upper troposphere/urban air close to ground/indoor/unspecified - emissions to water: ground-/ground-, long-term/ocean/surface water/unspecified-emissions to soil: agricultural/forestry/industrial/unspecified (more in Weidema et al. 2012)
} 
Table 2 Reporting of (first and second priority) properties of MNM releases for the inclusion into today's LCA data formats

\begin{tabular}{|c|c|c|c|c|}
\hline Criteria & Property type & Property & Value(s) & Remarks \\
\hline Composition & Defining property & Exchange name & Substance name & $\begin{array}{l}\text { Name, e.g. according to the naming rules of EcoInvent } \\
\text { (Weidema et al. 2012) }\end{array}$ \\
\hline Amount & Basic property & Mass amount & $m(\mathrm{~kg})$ & \\
\hline Shape & Additional property & Particle shape form & $\begin{array}{l}\mathrm{S}=\text { spherical } \\
\mathrm{F}=\text { fibrous }\end{array}$ & $\begin{array}{l}\text { Fibres have aspect ratio bigger 3:1 (WHO definition)-all } \\
\text { other particles are assumed of 'spherical' form }\end{array}$ \\
\hline \multirow[t]{3}{*}{ Size distribution } & Additional property & Average size & $\begin{array}{l}D_{\mathrm{A} / 50}(\mathrm{~nm}) \\
D_{\mathrm{Avg}}(\mathrm{nm})\end{array}$ & $\begin{array}{l}\text { For spherical MNM, the Median of 'equivalent area diameter' } \\
D_{\mathrm{A} / 50} \text { is reported/for fibrous } \mathrm{MNM} \text {, the medium diameter } D_{\mathrm{Avg}}\end{array}$ \\
\hline & \multirow[t]{2}{*}{ Additional property } & Size distribution resp. & $\begin{array}{l}D_{\mathrm{A} / 10}(\mathrm{~nm}) \\
D_{\mathrm{A} / 90}(\mathrm{~nm})\end{array}$ & $\begin{array}{l}\text { For spherical MNM, the 'equivalent area diameter' } \mathrm{D}_{\mathrm{A}} \text { are reported. } \\
\text { Its values are ideally based on SEM/TEM analysis (other, } \\
\text { appropriate analysis methods can be used as well) }\end{array}$ \\
\hline & & Length & $L(\mu \mathrm{m})$ & $\begin{array}{l}\text { For fibrous MNM, no size distribution, but the average length } \\
\text { of the fibres is reported }\end{array}$ \\
\hline
\end{tabular}

spherical form, as their actual form is of minor interest only for the actual modelling of their toxicological effects.

- Size (distribution): This property is added as an additional property in case of releases of MNM. It needs to be indicated by two elements, which are different for fibres respectively spherical releases. In case of fibrous MNM, this average size is characterised by the average diameter and the average length of these released MNM. For spherical MNM releases, the two elements are the 'average' size (expressed by the median size $D_{\mathrm{A} / 50}$ ) and the size distribution. The distribution is characterised by the values $D_{\mathrm{A} / 10}$, size values where $10 \%$ have a smaller size, and $D_{\mathrm{A} / 90}$, where $90 \%$ have a smaller size. All three values are based on the principle of 'equivalent area diameter, $D_{\mathrm{A}}$ ' (according to Merkus 2009b), i.e. 'diameter of a circle, having the same area as the particle's projection" ${ }^{\text {,7 This }}$ type of diameter is used, as (scanning or transmission) electron microscopy (SEM and TEM) techniques result in a number-based size distribution of equivalent area diameters (Merkus 2009a).

- Amount: This is a basic property, used similar as in traditional (i.e. non-MNM) releases. Actually, there is no other choice for the basic property, as shape, size (distribution) and surface conditions (i.e. all further 1st priority properties) are intrinsic properties ${ }^{8}$ and thus cannot be used as measurement units.

\footnotetext{
${ }^{7}$ As in reality most (non-fibrous) particles are not of a spherical form (Merkus 2009b); Merkus suggests in his publication for a less ambiguous way of reporting the use of the 'equivalent sphere concept'. However, within the 'equivalent sphere concept' various approaches exist (see, e.g. Fig. 2.2 in Merkus 2009b), which depend on the actual measurement technique used.

${ }^{8}$ According to Wikipedia, intrinsic means 'an essential or inherent property of a system or of a material itself or within. It is independent of how much of the material is present and is independent of the form the material, e.g., one large piece or a collection of smaller pieces. Intrinsic properties are dependent mainly on the chemical composition or structure of the material'.
}

Here, as stipulated in Section 4.1, the amount of MNM releases can be measured in two distinct ways: either as a mass amount or as a particle number concentration. The current scientific literature does not give a clear indication which of these two approaches is more appropriate/more important in the context of MNM releases. For example, in Boverhof and David (2010), the 'mass amount' is stipulated as the important property, while EC's SCENIHR ${ }^{9}$ Committee considers number size distribution the more relevant metric (EC-SCENIHR 2009). In fact, the results of the two ways are respectively linked, although the mathematical transformation from one to the other is usually not that straight forward. However, due to the simplification stipulated above that all non-fibrous particles are of spherical form, a clear mathematical relationships between the two values can be defined (the detailed formulas can be found in the Electronic Supplementary Material). Thus, the 'mass amount' shall be used here for this basic property. By this choice, a further defining property - i.e. the unit - is defined at the same time. Similar to 'traditional' flows (e.g. the amount of carbon dioxide emissions to air), the mass amount is used as basic property, defining the flows in 'kilogram'.

An advantage of using the mass amount as the basic property is the avoidance of a multiplication of the existing, very long list of elementary flows in current LCA databases and software systems. Then, that way, the existing list can be used also for MNM releases. The distinction between an emission in its bulk and its MNM form, e.g. for the subsequent impact assessment, is done by the inclusion of 'additional properties' (i.e. shape and size distribution). An example for such a distinction: the 'bulk' form of $\mathrm{TiO}_{2}$ to water is 'titanium dioxide, to water'; a release of the respective MNM is also called 'titanium dioxide, to water', but maintains for the

\footnotetext{
${ }^{9}$ SCENIHR: Scientific Committee on Emerging and Newly Identified Health Risks.
} 
additional properties 'shape' $=$ ' $\mathrm{S}$ ' (for spherical, as $\mathrm{TiO}_{2}$ in its nanoform is usually not of fiberous form) and 'size distribution' $D_{\mathrm{A} / 50}=45 \mathrm{~nm}, D_{\mathrm{A} / 10}=20 \mathrm{~nm}, D_{\mathrm{A} / 90}=70 \mathrm{~nm}$. Additional aspects are included on the level of inventory analysis, and the more information that can be included the more precise the picture of the release can be. This is important because precision here will be carried over in the subsequent impact assessment step.

However, according to the discussions with the toxicologists contacted, access to data concerning surface conditions, distinguishing several different, individual properties (e.g. Kendall and Holgate 2012; Sharifi et al. 2012; Pettitt and Lead 2013) - is much more difficult than to ensure the two properties listed above (i.e. shape and size). Thus, the framework here suggests limiting these additional properties of MNM releases in the first phase to 'shape' and 'size (distribution)'. The various elements covered by the issue of surface conditions can then be included in a later stage. Once these values have been investigated by the scientific community and documented in a broader and systematic way, it will be more clear which of these properties it makes sense to include, and in which way.

\section{Discussion and outlook}

To date, this publication is the only attempt known to show a clearly defined modelling framework concerning the integration of releases of MNM into air, water and soil respectively in current LCI models.

The reduction to a group of "key" properties suggested on the level of inventory models increases the uncertainty in this second step of the ISO framework for LCA, i.e. the inventory analysis. At the same time, the more properties that are required to model releases of MNM, the more data is needed and the longer it will take to collect the information. It is therefore important in such cases to take into account not only the scientific context but also to have feedback from respective experts in order to be able to prioritise the different material properties listed in Table 1 concerning their influence on the toxicological effects of the material. Because of this, the expert feedback compiled here was strongly weighted in the establishment of the framework proposed in this current publication.

Size and shape distribution represent two characteristics that a priori can be more easily measured than $X Y Z$ characteristics that are not as easily understood. As a consequence, no default values were given in the description here. Keeping in mind the fact that released MNM can have very different properties compared to the original MNM and the fact that chemically identical MNM can be produced in very different sizes and forms (as described, e.g. in Euliss et al. 2006), a definition of such default values seems neither feasible nor meaningful. The data availability for most of the further properties listed in Table 1 is weak according to expert knowledge. Therefore a more detailed inventory model (by including further properties) would not automatically have a decreased uncertainty. In fact, the opposite may even be true as a higher number of properties would need estimation procedures for a respective integration. Thus, the framework proposed here can be estimated to be a good compromise between scholarly knowledge and (toxicological) reality.

Only a broad testing of this framework in various situations, by different case studies (covering different types of MNM), will show in the end if the simplifications and reductions made here keep the characterisation of MNM releases specific enough. This would ensure to assess respective emissions accurately. A next step must come from the impact assessment by an estimation of CFs for the most important MNM as a function of shape and size (distribution) of the expected release. In parallel to this, average production inventory datasets for the most important MNM (using, e.g. the five top materials listed in Ogilvie Hendren et al. 2011, as starting point) have to be established and published. This could be most useful by integrating this information into the most used LCI databases (e.g. ecoinvent or ELCD database). Today, only once such CFs and average datasets are available; the methodology described herein could be readily tested in different case studies.

Currently used and accessible LCI databases and LCIA methods often do not distinguish different forms of "bulk" releases (e.g. releases of metals into water are rarely further specified according to their oxidation state - but summarised in one single number only). As already mentioned in Section 1.3, PM emissions are currently spread into a maximum of three different size groups, but no substance specific information can be found in these PM flows. In other words, it is currently not possible to identify eventual double counting, especially in cases where one substance is reported as part of the PM emission and as an individual emission. Therefore, a change of all releases to the here described, substance-specific modelling principles, would allow one to avoid such potential double counting on the level of bulk releases. Admittedly, it would require a detailed, substance-specific characterisation of all PM flows in the existing LCA databases, which may not be available for some time.

Acknowledgments This research was internally funded by Empa and externally by the project 'NanoHouse' (grant number 247'810), research project in the 7th Framework Program of the European Commission. Stefanie Hellweg (from ETH Zürich), Harald Krug, Dominic Notter, Bernd Nowack, Claudia Som and Peter Wick (all from Empa) are acknowledged for their valuable inputs during all the discussions for establishing the here described framework while Denise Mitrano (Empa) is acknowledged for the thorough English language check. Last but not least, I would acknowledge the very helpful comments from the reviewers, allowing me to present in the end a more consistent and more clear final version of this paper. 


\section{References}

Albanese A, Tang PS, Chan WCW (2012) The effect of nanoparticle size, shape, and surface chemistry on biological systems. Annu Rev Biomed Eng 14:1-16. doi:10.1146/annurev-bioeng-071811-150124

Alvarez PJJ, Colvin VL, Lead JR, Stone V (2009) Research priorities to advance eco-responsible nanotechnology. ACS Nano 3(7):16161619

Aschberger K, Micheletti C, Sokull Klüttgen B, Christensen FM (2011) Analysis of currently available data for characterising the risk of engineered nanomaterials to the environment and human healthlessons learned from four case studies. Environ Int 37(6):1143-1156

Asmatulu E, Twomey J, Overcash MR (2012) Life cycle and nanoproducts: end-of-life assessment. J Nanoparticle Res 14:720. doi: 10.1007/s11051-012-0720-0

Bakand S, Hayes A, Dechsakulthorn F (2012) Nanoparticles: a review of particle toxicology following inhalation exposure. Inhal Toxicol 24(2):125-135. doi:10.3109/08958378.2010.642021

Bouwmeester H, Lynch I, Marvin HJP, Dawson KA, Berges M, Braguer D, Bryne HJ, Casey A, Chambers G, Clift MJD, Elia G, Fernandes TF, Fjellsbo LM, Hatto P, Juillerat L, Klein C, Kreyling WG, Nickel C, Riediker M, Stone V (2011) Minimal analytical characterisation of engineered nanomaterials needed for hazard assessment in biological matrices. Nanotoxicology 5(1):1-11

Boverhof DR, David RM (2010) Nanomaterial characterization: considerations and needs for hazard assessment and safety evaluation. Anal Bioanal Chem 396:953-961. doi:10.1007/s00216-009-3103-3

Card JW, Magnuson BA (2009) Letter to the editor: proposed minimum characterization parameters for studies on food and food-related nanomaterials. J Food Sci 74(8):vi-vii

Charron A, Harrison RM (2009) Atmospheric nanoparticles. In: Lead JR, Smith E (eds) Environmental and human health impacts of nanotechnology. Blackwell, London, pp 163-209

Choi S-J, Choy J-H (2011) Effect of physico-chemical parameters on the toxicity of inorganic nanoparticles. J Mater Chem 21:5547-5554

Clark K, van Tongeren M, Christensen FM, Brouwer D, Nowack B, Gottschalk F, Micheletti C, Schmid K, Gerritsen R, Aitken R, Vaquero C, Gkanis V, Housiades C, López de Ipiña JM, Riediker $M$ (2012) Limitations and information needs for engineered nanomaterial-specific exposure estimation and scenarios: recommendations for improved reporting practices. J Nanoparticle Res 14:970. doi:10.1007/s11051-012-0970-x

Crane M, Handy RD, Garrod J, Owen R (2008) Ecotoxicity test methods and environmental hazard assessment for engineered nanoparticles. Ecotoxicology 17:412-437

de Figueirêdo MCB, Rosa MF, Ugaya CML, Moreira de Souza Filho MS, Carneiro da Silva Braid AC, Braid AC, de Melo LFL (2012) Life cycle assessment of cellulose nanowhiskers. J Clean Prod 35:130 139

Demou E, Stark WJ, Hellweg S (2009) Particle emission and exposure during nanoparticle synthesis in research laboratories. Ann Occup Hyg 53(8):829-838

Deorsola FA, Russo N, Blengini GA, Fino D (2012) Synthesis, characterization and environmental assessment of nanosized MoS2 particles for lubricants applications. Chem Eng J 195-196:1-6. doi:10. 1016/j.cej.2012.04.080

Donaldson K, Tran CL (2004) An introduction to the short-term toxicology of respirable industrial fibres. Mutat Res 553(1-2):5-9

EC (2011) Commission Recommendation of 18 October 2011 on the definition of nanomaterial. 2011/696/EU. Official Journal of the European Union, Brussels

EC-JRC (2010a) Analysis of existing environmental impact assessment methodologies for use in life cycle assessment. ILCD handbookInternational Reference Life Cycle Data System. European Commission - Joint Research Centre (EC-JRC), Ispra
EC-JRC (2010b) Framework and requirements for life cycle impact assessment models and indicators. ILCD handbook-International Reference Life Cycle Data System. European Commission-Joint Research Centre (EC-JRC), Ispra

EC-JRC (2010c) General guide for life cycle assessment - detailed guidance. ILCD handbook - International Reference Life Cycle Data System. European Commission-Joint Research Centre (EC-JRC), Ispra

EC-JRC (2010d) Specific guide for life cycle inventory datasets. ILCD handbook-International Reference Life Cycle Data System. European Commission- Joint Research Centre (EC-JRC), Ispra

EC-JRC (2011) Recommendations for life cycle impact assessment in the European context - based on existing environmental impact assessment models and factors. ILCD handbook-International Reference Life Cycle Data System. European Commission-Joint Research Centre (EC-JRC), Ispra

EC-JRC (2012) ILCD Format SDK 1.1. European Commission, Joint Research Centre (EC-JRC). http://lca.jrc.ec.europa.eu/lcainfohub/ developerDownload.vm. Accessed 3 Oct 2012

Eckelman MJ, Mauter MS, Isaacs JA, Elimelech M (2012) New perspectives on nanomaterial aquatic ecotoxicity: production impacts exceed direct exposure impacts for carbon nanotubes. Environ Sci Technol 46:2902-2910

ecoinvent Centre (2010) EcoSpold v2 Data Format. http://www. ecoinvent.org/ecoinvent-v3/ecospold-v2/. Accessed 3 Jan 2011

ecoinvent Centre (2013) ecoinvent data v3.01. Swiss Centre for Life Cycle Inventories, Dübendorf

EC-SCENIHR (2009) Risk assessment of products of nanotechnologies. European Commission-Scientific Committee on Emerging and Newly Identified Health Risks (EC-SCENIHR), Brussels

ED, DP (2007) Nano risk framework. Environmental Defense/DuPont, Washington/Wilmington

Euliss LE, DuPont JA, Gratton S, DeSimone J (2006) Imparting size, shape, and composition control of materials for nanomedicine. Chem Soc Rev 35:1095-1104. doi:10.1039/b600913c

Farré M, Sanchís J, Barceló D (2011) Analysis and assessment of the occurrence, the fate and the behavior of nanomaterials in the environment. Trends Anal Chem 30(3):517-527

Finnveden G, Hauschild M, Ekvall T, Guinee J, Heijungs R, Hellweg S, Koehler A, Pennington D, Suh S (2009) Recent developments in life cycle assessment. J Environ Manag 91:1-21

Frischknecht R, Jungbluth N, Althaus H-J, Doka G, Dones R, Hischier R, Hellweg S, Nemecek T, Rebitzer G, Spielmann M (2007) Overview and methodology. Swiss Centre for Life Cycle Inventories, Duebendorf

Fubini B, Ghiazza M, Fenoglio I (2010) Physio-chemical features of engineered nanoparticles relevant to their toxicity. Nanotoxicology 4(4):347-363

Gavankar S, Suh S, Keller AF (2012) Life cycle assessment at nanoscale: review and recommendations. Int J Life Cycle Assess 17:295-303. doi:10.1007/s11367-011-0368-5

Goedkoop M, Heijungs R, Huijbregts MAJ, de Schreyver A, Struijs J, Van Zelm R (2012) ReCiPe 2008 - a life cycle impact assessment method which comprises harmonised category indicators at the midpoint and the endpoint level. First edition (revised)/Report I: Characterisation. VROM-Ministery of Housing Spatial Planning and Environment, Den Haag

Gottschalk F, Nowack B (2011) The release of engineered nanomaterials to the environment. J Environ Monit 13:1145-1155

Gottschalk F, Sonderer T, Scholz RW, Nowack B (2009) Modeled environmental concentrations of engineered nanomaterials $\left(\mathrm{TiO}_{2}, \mathrm{ZnO}\right.$, $\mathrm{Ag}, \mathrm{CNT}$, fullerenes) for different regions. Environ Sci Technol 43: 9216-9222

Handy RD, Owen R, Valsami-Jones E (2008a) The ecotoxicology of nanoparticles and nanomaterials: current status, knowledge gaps, challenges, and future needs. Ecotoxicology 17(5):315-325 
Handy RD, Von der Kammer F, Lead JR, Hassellöv M, Owen R, Crane M (2008b) The ecotoxicology and chemistry of manufactured nanoparticles. Ecotoxicology 17(4):287-314

Hansen SF, Larsen BH, Olsen SI, Baun A (2007) Categorization framework to aid hazard identification of nanomaterials. Nanotoxicology 1(3):243-250

Hassellöv M, Kägi R (2009) Analysis and characterization of manufactured nanoparticles in aquatic environments. In: Lead JR, Smith E (eds) Environmental and human health impacts of nanotechnology. Blackwell, London, pp 211-266

Hischier R, Walser T (2012) Environmental sustainability assessment of engineered nanomaterials: state of art \& strategies to overcome existing gaps. Sci Total Environ 425:271-282

Hischier R, Baitz M, Bretz R, Frischknecht R, Jungbluth N, Marheineke T, McKeown P, Oele M, Osset P, Renner I, Skone T, Wessman H, de Beaufort ASH (2001) Guidelines for consistent reporting of exchanges from/to nature within life cycle inventories (LCI). Int J Life Cycle Assess 6(4):192-198

Horie M, Fujita K (2011) Toxicity of metal oxides nanoparticles. Adv Mol Toxicol 5:145-178

ISO (2006a) Environmental management—-life cycle assessment—principles and framework. International Standardization Organization (ISO), European Standard EN ISO 14'040, Geneva

ISO (2006b) Environmental management-life cycle assessment-requirements and guidelines. International Stanardisation Organisation (ISO), European Standard EN ISO 14'044, Geneva

ISO (2010) Nanotechnologies_vocabulary-part 1: core terms. International Stanardisation Organisation (ISO), Technical Specification ISO/TS 80004-1, Geneva

ISO (2012) Nanotechnologies - guidance on physico-chemical characterization of engineered nanoscale materials for toxicologic assessment. International Stanardisation Organisation (ISO), Technical Report ISO/TR 13014:2012, Geneva

Kendall M, Holgate S (2012) Health impact and toxicological effects of nanomaterials in the lung. Respirology 17:743-758. doi:10.1111/j. 1440-1843.2012.02171.x

Klaessig F, Marrapese M, Shuji A (2011) Current perspectives in nanotechnology terminology and nomenclature. In: Murashov V, Howard J (eds) Nanotechnology standards. Springer, Berlin. doi: 10.1007/978-1-4419-7853-0 2

Klaine SJ, Koelmans AA, Horne N, Carley S, Handy RD, Kapustka L, Nowack B, Von der Kammer F (2012) Paradigms to assess the environmental impact of manufactured nanomaterials. Environ Toxicol Chem 31(1):3-14

Köhler A, Som C, Helland A, Gottschalk F (2008) Studying the potential release of carbon nanotubes throughout the application life cycle. J Clean Prod 16(8-9):927-937

Krug HF, Wick P (2011) Nanotoxicology: an interdisciplinary challenge. Angew Chem Int Ed Engl 50:1260-1278

Krug HF, Wick P, Nowack B, Müller N (2013) Human and ecotoxicity of synthetic nanomaterials. Initial insights for major accident prevention. Environmental Studies No. 1301. Swiss Federal Office for the Environment (FOEN), Bern

Labille J, Brant J (2010) Stability of nanoparticles in water. Nanomedicine (Lond) 5(6):985-998

LeCorre D, Hohenthal C, Dufresne A, Bras J (2013) Comparative sustainability assessment of starch nanocrystals. J Polym Environ 21(1):71-80

Lin D, Tian X, Wu F, Xing B (2010) Fate and transport of engineered nanomaterials in the environment. J Environ Qual 39:1896-1908

Love SA, Maurer-Jones MA, Thompson JW, Lin Y-S, Haynes CL (2012) Assessing nanoparticle toxicity. Annu Rev Anal Chem (Palo Alto, Calif) 5:181-205

Lowry GV, Hotze EM, Bernhardt ES, Dionysiou D, Pedersen JA, Wiesner MR, Xing B (2010) Environmental occurrences, behavior, fate and ecological effects of nanomaterials: an introduction to the special series. J Environ Qual 39:1867-1874

Merkus HG (2009a) Overview of size characterisation techniques. In: Merkus HG (ed) Particle size measurements: fundamentals, practice, quality. vol 17 of Particle Technology Series. Springer, Dordrecht

Merkus HG (2009b) Particle size, size distribution and shape. In: Merkus HG (ed) Particle size measurements: fundamentals, practice, quality. vol 17 of Particle Technology Series. Springer, Dordrecht

MINChar Initiative (2008) Recommended minimum physical and chemical parameters for characterizing nanomaterials on toxicology studies: MINChar physiochemical parameters list. Woodrow Wilson International Center for Scholars: Washington

Motzkus C, Chivas-Joly C, Guillaume E, Ducourtieux S, Saragoza L, Lesenechal D, Macé T (2011) Characterisation of aerosol emitted by the combustion of nanocomposites. J Phys Conf Ser 304:10. doi:10. 1088/1742-6596/304/1/012020

Nanocap (2009) Measurement techniques for nanoparticles

Nel A, Xia T, Mädler L, Li N (2006) Toxic potential of materials at the nanolevel. Science 311:622-627

Ness B, Urbel-Piirsalu E, Anderberg S, Olsson L (2007) Categorising tools for sustainability assessment. Ecol Econ 60:498-508

Nowack B, Ranville JF, Diamond S, Gallego-Urrea JA, Metcalfe C, Rose J, Horne N, Koelmans AA, Klaine SJ (2012) Potential scenarios for nanomaterial release and subsequent alteration in the environment. Environ Toxicol Chem 31(1):50-59

Oberdörster G, Stone V, Donaldson K (2007) Toxicology of nanoparticles: a historical perspective. Nanotoxicology 1(1):2-25

OECD (2010) Guidance manual for the testing of manufactured nanomaterials: OECD Sponsorship Programme. Environment, Health and Safety Publications-series on the safety of manufactured nanomaterials. OECD Environment Directorate Environment, Health and Safety Devision, Paris

OECD (2012) Important issues on risk assessment of manufactured nanomaterials. Environment, Health and Safety Publications-series on the safety of manufactured nanomaterials. OECD Environment Directorate Environment, Health and Safety Devision, Paris

Ogilvie Hendren C, Mesnard X, Dröge J, Wiesner MR (2011) Estimating production data for five engineered nanomaterials as a basis for exposure assessment. Environ Sci Technol 45:2562-2569

Peralta-Videa JR, Zhao L, Lopez-Moreno ML, de la Rosa G, Hong J, Gardea-Torresdey JL (2011) Nanomaterials and the environment: a review from the biennium 2008-2010. J Hazard Mater 186:1-15

Pettitt ME, Lead JR (2013) Minimum physicochemical characterisation requirements for nanomaterial regulation. Environ Int 52:41-50. doi:10.1016/j.envint.2012.11.009

Piccinno F, Gottschalk F, Seeger S, Nowack B (2012) Industrial production quantities and uses of ten engineered nanomaterials in Europe and the world. J Nanoparticle Res 14(1109):11

Rosenbaum R, Bachmann TM, Swirsky Gold L, Huijbregts MAJ, Jolliet O, Juraske R, Koehler A, Larsen HF, MacLeod M, Margni M, McKone T, Payet J, Schuhmacher M, Van de Meent D, Hauschild M (2008) USEtox - the UNEP-SETAC toxicity model: recommended characterisation factors for human toxicity and freshwater ecotoxicity in life cycle impact assessment. Int J Life Cycle Assess 13:532-546

Salieri B (2013) The challenges and the limitations in life cycle impact assessment for metal oxide nanoparticles, a case study on nano$\mathrm{TiO}_{2}$. Università di Bologna, Bologna

Sanchís J, Farré M, Barceló D (2012) Analysis and Fate of Organic Nanomaterials in Environmental Samples. Comprehensive Analytical Chemistry 59 (Chapter 4):131-168

Sayes CM, Warheit DB (2009) Characterisation of nanomaterials for toxicity assessment. Wiley Interdiscip Rev Nanomed Nanobiotechnol 1(6):660-670 
Schrand AM, Rahman MF, Hussain SM, Schlager JJ, Smith DA, Syed AF (2010) Metal-based nanoparticles and their toxicity assessment. Wiley Interdiscip Rev Nanomed Nanobiotechnol 2(5):544-568

Scown TM, van Aerle R, Tyler CR (2010) Review: do engineered nanoparticles pose a significant threat to the aquatic environment? Crit Rev Toxicol 40(7):653-670

SETAC Guidelines for life-cycle assessment: a "Code of Practice". SETAC Workshop, Sesimbra (Portugal), March 31 to April 3, 1993. Society of Environmental Toxicology and Chemistry (SETAC), Brussels and Pensacola

Sharifi S, Behzadi S, Laurent S, Laird Forrest M, Stroeve P, Mahmoudi M (2012) Toxicity of nanomaterials. Chem Soc Rev 41:2323-2343

Smita S, Gupta SK, Bartonova A, Dusinska M, Gutleb AC, Rahman Q (2012) Nanoparticles in the environment: assessment using the causal diagram approach. Environ Health 11(Suppl 1):S13

Som C, Nowack B, Krug HF, Wick P (2013) Toward the development of decision supporting tools that can be used for safe production and use of nanomaterials. Acc Chem Res 46(3):863-72. doi:10.1021/ ar3000458

Sonnemann G, Vigon B (eds) (2011) Global guidance principles for life cycle assessment databases. A basis for greener processes and products. UNEP/SETAC Life Cycle Initiative. United Nations Environment Programme (UNEP), Paris

Starbova K, Petrov D, Starbov N, Lovchinov V (2012) Synthesis of supported fibrous nanoceramics via electrospinning. Ceram Int 38: 4645-4651. doi:10.1016/j.ceramint.2012.02.046

Stone V, Hankin S, Aitken R, Aschberger K, Baun A, Christensen F, Fernandes T, Foss Hansen S, Bloch Hartmann N, Hutchison G, Johnston H, Micheletti C, Peters S, Ross B, Sokull-Kluettgen B, Stark D, Tran L (2009) Engineered nanoparticles: review of health and environmental safety (ENRHES). Project final report. Napier University, Edinburgh
Stone V, Nowack B, Baun A, van den Brink N, von der Kammer F, Dusinska M, Handy R, Hankin S, Hassellöv M, Joner E, Fernandes TF (2010) Nanomaterials for environmental studies: classification, reference material issues, and strategies for physico-chemical characterisation. Sci Total Environ 408:1745-1754

Tiede K, Boxall ABA, Tear SP, Lewis J, David H, Hassellöv M (2008) Detection and characterization of engineered nanoparticles in food and the environment. Food Addit Contam Part A Chem Anal Control Expo Risk Assess 25(7):795-821

Upadhyayula VKK, Meyer DE, Curran MA, Gonzalez MA (2012) Life cycle assessment as a tool to enhance the environmental performance of carbon nanotube products: a review. J Clean Prod 26: $37-47$

Walser T, Demou E, Lang DJ, Hellweg S (2011) Prospective environmental life cycle assessment of nanosilver t-shirts. Environ Sci Technol 45(10):4570-4578

Walser T, Hellweg S, Juraske R, Luechinger NA, Wang J, Fierz M (2012) Exposure to engineered nanoparticles: model and measurements for accident situations in laboratories. Sci Total Environ 420:119-126. doi:10.1016/J.scitotenv.2012.01.038

Warheit DB, Sayes CM, Reed KL, Swain KA (2008) Health effects related to nanoparticle exposures: environmental, health and safety considerations for assessing hazards and risks. Pharmacol Ther 120(1):35-42

Warheit DB, Reed KL, Sayes CM (2009) A role for nanoparticle surface reactivity in facilitating pulmonary toxicity and development of a base set of hazard assays as a component of nanoparticle risk management. Inhal Toxicol 21(S1):61-67

Weidema B, Bauer C, Hischier R, Nemecek T, Wernet G (2012) Overview and methodology. Data quality guideline for the ecoinvent database version 3. Final version (revision 2). ecoinvent Centre (Swiss Centre for Life Cycle Inventories), St. Gallen (Switzerland) 